Pacific Journal of Mathematics

DUAL MIXED VOLUMES 


\section{DUAL MIXED VOLUMES}

\section{ERWIN LUTWAK}

A concept dual to the mixed volumes of Minkowski is introduced. Duals to the classical mixed volume inequalities of Minkowski, Fenchel and Aleksandrov are presented. As an application of this work a sharp isoperimetric inequality relating the mean width of a convex body and the cross-sectional measures of its polar body is obtained. This inequality implies that of all convex bodies of a given mean width the $n$-ball (centered at the origin) is the one whose polar body has minimal cross-sectional measures of any index. It further gives a sharp lower bound for the product of the mean widths of a convex body and its polar body.

The setting for this paper will be Euclidean $n$-space $R^{n}$. Convex, compact sets with nonempty interiors are called convex bodies. All convex bodies are assumed to contain the origin in their interiors and the space of all such convex bodies with the Hausdorff topology will be denoted by $\mathscr{K}_{n}$. Convex bodies will be denoted by capital letters such as $A, B, K$. Vectors in $R^{n}$ are denoted by lower case letters such as $a, u, x$. Scalars are denoted by lower case Greek letters such as $\alpha, \mu, \lambda$.

The unit $n-1$ sphere and the unit $n$-ball are denoted by $\Omega$ and $U$, respectively. The volume of the unit $n$-ball is denoted by $\omega_{n}$. For a convex body $A$ the $n$-dimensional volume and surface area will be denoted by $V(A)$, and $S(A)$, respectively. The diameter and mean width of $A$ will be denoted by $D(A)$ and $\bar{b}(A)$, respectively. The radial function of $A \rho_{A}$ is defined on $\Omega$ by:

$$
\rho_{A}(u)=\operatorname{Sup}\{\lambda>0 \mid \lambda u \in A u \in \Omega\}
$$

The polar body of $A$ (with respect to the unit sphere centered at the origin) will be denoted by $A^{*}$.

Given $n$ convex bodies $A_{1}, \cdots, A_{n}$ their mixed volume will be denoted by $V\left(A_{1}, \cdots, A_{n}\right)$. For convex bodies $A$ and $B$ we use $V_{i}(A, B)$ to denote

$$
V(\underbrace{A, \cdots, A}_{n-i}, \underbrace{B, \cdots, B}_{i})
$$


and $W_{i}(A)$ to denote $V_{i}(A, U)$. For reference see Bonnesen and Fenchel [4].

We begin by defining the dual mixed volumes.

DEFINITION 1.

$$
\tilde{V}\left(A_{1}, \cdots, A_{n}\right)=\frac{1}{n} \int_{\Omega} \rho_{A_{1}}(u) \cdots \rho_{A_{n}}(u) d S(u) \quad\left[A_{i} \in \mathscr{K}_{n}\right]
$$

where $d S$ signifies the area element on $\Omega$.

DEFINITION 2.

$$
\tilde{V}_{i}(A, B)=\tilde{V}(\underbrace{A, \cdots, A}_{n-i}, \underbrace{B, \cdots, B}_{i}) \quad\left[A, B \in \mathscr{K}_{n}\right] .
$$

The dual cross-sectional measures are the special dual mixed volumes defined by:

DEFINITION 3.

$$
\tilde{W}_{i}(A)=\tilde{V}_{i}(A, u)
$$

By definition $1, \tilde{V}$ is a map

$$
\tilde{V}: \underbrace{\mathscr{K}_{n} \times \cdots \times \mathscr{K}_{n}}_{n} \rightarrow R
$$

We list some of its elementary properties.

(1) $\tilde{V}$ is continuous;

(2) $\tilde{V}\left(A_{1}, \cdots, A_{n}\right)>0$;

(3) $\tilde{V}\left(\lambda_{1} A_{1}, \cdots, \lambda_{n} A_{n}\right)=\lambda_{1} \cdots \lambda_{n} \tilde{V}\left(A_{1}, \cdots, A_{n}\right) \quad\left[\lambda_{i}>0\right]$;

(4) If $A_{i} \subset B_{i}$, for all $i$, then $\tilde{V}\left(A_{1}, \cdots, A_{n}\right) \leqq \tilde{V}\left(B_{1}, \cdots, B_{n}\right)$ with equality iff $A_{i}=B_{i}$ for all $i$;

(5) $\tilde{V}(A, \cdots, A)=V(A)$.

By definition 3, $\tilde{W}_{i}$ is a map

$$
\tilde{W}_{i}: \mathscr{K}_{n} \rightarrow R .
$$

It is continuous, bounded, positive, rotation invariant, homogeneous of degree $n-i$ and monotone under set inclusion. 
As defined in 2 and 3, $\tilde{V}_{i}$ and $\tilde{W}_{i}$ have indices $i$ restricted to integer values between 0 and $n$. We now extend the definitions so that $\tilde{V}_{i}$ and $\tilde{W}_{i}$ are defined for all real indices. The extended definitions will be required to prove Theorem 4 .

DEFINITION 2*.

$$
\tilde{V}_{i}(A, B)=\frac{1}{n} \int_{\Omega} \rho_{A}^{n-i}(u) \rho_{B}^{i}(u) d S(u) \quad\left[A, B \in \mathscr{K}_{n} i \in R\right]
$$

Definition 3*.

$$
\tilde{W}_{i}(A)=\tilde{V}_{i}(A, U)
$$$$
\left[A \in \mathscr{K}_{n} i \in R\right]
$$

The following simple extension of Hölder's Inequality will be required to prove our main theorems.

Lemma 1. If $f_{0}, f_{1}, \cdots, f_{m}$ are (strictly) positive continuous functions defined on $\Omega$ and $\alpha_{1}, \cdots, \alpha_{m}$ are positive constants the sum of whose reciprocals is unity, then

$$
\int_{\Omega} f_{0}(u) f_{1}(u) \cdots f_{m}(u) d S(u) \leqq \prod_{i=1}^{m}\left[\int_{\Omega} f_{0}(u) f_{i}^{\alpha_{i}}(u) d S(u)\right]^{1 / \alpha_{i}}
$$

with equality iff there exist positive constants $\lambda_{1}, \cdots, \lambda_{m}$ such that $\lambda_{1} f_{1}^{\alpha_{1}}(u)=\cdots=\lambda_{m} f_{m}^{\alpha_{m}}(u)$ for all $u \in \Omega$.

The following general inequality between mixed volumes is due to Aleksandrov [1] (or see [5]):

$$
\prod_{i=0}^{m-1} V\left(A_{1}, \cdots, A_{n-m}, A_{n-i}, \cdots, A_{n-i}\right) \leqq V^{m}\left(A_{1}, \cdots, A_{n}\right) \quad[1<m \leqq n]
$$

THEOREM 1.

$$
\tilde{V}^{m}\left(A_{1}, \cdots, A_{n}\right) \leqq \prod_{i=0}^{m-1} \tilde{V}\left(A_{1}, \cdots, A_{n-m}, A_{n-i}, \cdots, A_{n-i}\right) \quad[1<m \leqq n]
$$

with equality iff $A_{n-m+1}, A_{n-m+2}, \cdots, A_{n}$ are all dilations of each other (with the origin as the center of dilation). 
To prove this we use Lemma 1 with

$$
\begin{aligned}
& \alpha_{i}=m \quad[i=1, \cdots, m], f_{0}=\rho_{A_{1}} \cdots \rho_{A_{n-m}} \quad\left(f_{0}=1 \text { if } m=n\right), \\
& \text { and } f_{i}=\rho_{A_{n-i+1}}[i=1, \cdots, m] .
\end{aligned}
$$

For $m=n$ Theorem 1 becomes:

Corollary 1.1.

$$
\tilde{V}^{n}\left(A_{1}, \cdots, A_{n}\right) \leqq V\left(A_{1}\right) \cdots V\left(A_{n}\right)
$$

with equality iff the $A_{i}$ are all dilations of each other (with the origin as the center of dilation).

We combine this with the aforementioned inequality of Aleksandrov (for $m=n$ ) and obtain:

Corollary 1.2.

$$
\tilde{V}\left(A_{1}, \cdots, A_{n}\right) \leqq V\left(A_{1}, \cdots, A_{n}\right)
$$

with equality iff the $A_{i}$ are all dilations of each other (with the origin as the center of dilation).

Corollary 1.3 .

$$
\tilde{V}_{i}(A, B) \leqq V_{i}(A, B) \quad[0<i<n]
$$

with equality iff $A$ is a dilation of $B$ (with the origin as the center of dilation).

Corollary 1.4.

$$
\tilde{W}_{i}(A) \leqq W_{i}(A) \quad[0<i<n]
$$

with equality iff $A$ is an $n$-ball (centered at the origin).

A special case of Corollary 1.1 are the 


\section{DUAL MINKOWSKI INEQUALITIES.}

Corollary 1.5 .

$$
\tilde{V}_{1}^{n}(A, B) \leqq V^{n-1}(A) V(B) \text { and } \tilde{V}_{n-1}^{n}(A, B) \leqq V(A) V^{n-1}(B)
$$

with equality iff $A$ is a dilation of $B$ (with the origin as the center of dilation).

Our principal inequality between the $\tilde{V}_{i}$ 's is given in:

THEOREM 2.

$$
\tilde{V}_{j}^{k-i}(A, B) \leqq \tilde{V}_{i}^{k-j}(A, B) \tilde{V}_{k}^{j-i}(A, B) \quad[i<j<k i, j, k \in R]
$$

with equality iff $A$ is a dilation of $B$ (with the origin as the center of dilation).

To prove this we use Lemma 1 with $m=2$,

$$
\begin{aligned}
& f_{0}=\rho_{A}^{n-i} \rho_{B}^{i}, \quad f_{1}=\rho_{A}^{i-j} \rho_{B}^{j-i}, \quad f_{2}=1, \quad \alpha_{1}=(k-i) /(j-i) \\
& \text { and } \alpha_{2}=(k-i) /(k-j) .
\end{aligned}
$$

We note that if the indices $i, j, k$ are restricted to integer values between 0 and $n$, then the inequality of Theorem 2 is a special case of Theorem 1. However, the more general inequality of Theorem 2 will be required to prove Theorem 4 .

The following are special cases of Theorem 2:

Corollary 2.1 .

$$
\tilde{V}_{i}(A, B) \leqq V^{(n-i) / n}(A) V^{i / n}(B) \quad[0<i<n \quad i \in R]
$$

with equality iff $A$ is a dilation of $B$ (with the origin as the center of dilation).

Corollary 2.2 .

$$
\tilde{W}_{i}(A) \leqq V^{(n-i) / n}(A) \omega_{n}^{i / n} \quad[0<i<n \quad i \in R]
$$

with equality iff $A$ is an $n$-ball (centered at the origin). 
Let $\mathrm{U}_{0}$, be an $n$-ball (centered at the origin).

THEOREM 3.

$\tilde{W}_{i}(A) \leqq \tilde{W}_{i}\left(U_{0}\right) \quad\left[V(A)=V\left(U_{0}\right) \quad 0<i<n \quad i \in R\right]$

with equality iff $A=U_{0}$.

Proof. Consider $A \in \mathscr{K}_{n}$ such that $V(A)=V\left(U_{0}\right)$. From Corollary 2.2 we deduce:

$$
\tilde{W}_{i}(A) \leqq V^{(n-i) / n}(A) \omega_{n}^{i / n}=V^{(n-i) / n}\left(U_{0}\right) \omega_{n}^{i / n}=\tilde{W}_{i}\left(U_{0}\right) .
$$

However, if $A$ is not an $n$-ball (centered at the origin), then Corollary 2.2 states that

$$
\tilde{W}_{i}(A)<V^{(n-i) / n}(A) \omega_{n}^{i / n}
$$

The following relation between $\bar{b}(A)$ and $W_{n-1}(A)$ is known (Hadwiger [9]):

$$
W_{n-1}(A)=2^{-1} \omega_{n} \bar{b}(A)
$$

LEMma 2.

$$
\tilde{W}_{n+1}\left(A^{*}\right)=W_{n-1}(A) \quad\left[A \in \mathscr{K}_{n}\right]
$$

Proof.

$$
\tilde{W}_{n+1}\left(A^{*}\right)=\frac{1}{n} \int_{\Omega} \rho_{A^{*}}^{-1}(u) d S(u)=\frac{1}{n} \int_{\Omega} H_{A}(u) d S(u)=2^{-1} \omega_{n} \bar{b}(A),
$$

where $H_{A}$ is the support function of $A$.

As an application of our work we present the following isoperimetric inequality:

TheOREM 4.

$$
\omega_{n}^{n-i+1} W_{n-1}^{i-n}(A) \leqq W_{i}\left(A^{*}\right) \quad[0 \leqq i<n]
$$

with equality iff $A$ is an $n$-ball (centered at the origin). 
Proof. From Theorem 2, with $(i, j, k)=(i, n, n+1)$ and $B=U$, we obtain:

$$
\omega_{n}^{n-i+1}=\tilde{W}_{n}^{n-i+1}\left(A^{*}\right) \leqq \tilde{W}_{i}\left(A^{*}\right) \tilde{W}_{n+1}^{n-i}\left(A^{*}\right)
$$

with equality iff $A$ is an $n$-ball (centered at the origin). From Corollary 1.4 we have:

$$
\tilde{W}_{i}\left(A^{*}\right) \leqq W_{i}\left(A^{*}\right)
$$

with equality if $A$ is an $n$-ball (centered at the origin).

The desired result is obtained when we combine (1) and (2) and apply Lemma 2.

If we let $i=0$ in Theorem 4 we obtain the

DUAL URYSOHN INEQUALITY.

Corollary 4.1 .

$$
2^{n} \omega_{n} \bar{b}(A)^{-n} \leqq V\left(A^{*}\right)
$$

with equality iff $A$ is an $n$-ball (centered at the origin).

This immediately yields the

\section{DUAL BIEBERBACH INEQUALITY.}

Corollary 4.2.

$$
2^{n} \omega_{n} D(A)^{-n} \leqq V\left(A^{*}\right)
$$

with equality iff $A$ is an $n$-ball (centered at the origin).

Santaló [10] has shown that a convex body $A$ can be repositioned in $R^{n}$ so that $V(A) V\left(A^{*}\right) \leqq \omega_{n}^{2}$. This result can be combined with the Dual Urysohn Inequality and the Dual Bieberbach Inequality to yield the Urysohn Inequality [12] and the Bieberbach Inequality [3].

Steinhardt [11] showed that for plane convex bodies

$$
4 \omega_{2}^{2} \leqq S(A) S\left(A^{*}\right) \quad\left[A \in \mathscr{K}_{2}\right]
$$


If we let $i=n-1$ in Theorem 4 we see that an $n$-space generalization of this is:

COROllary 4.3.

$$
\omega_{n}^{2} \leqq W_{n-1}(A) W_{n-1}\left(A^{*}\right) \quad\left[A \in \mathscr{K}_{n}\right]
$$

with equality iff $A$ is an $n$-ball (centered at the origin).

This was obtained by Firey [7] for dimensions 2 and 3.

This inequality raises the question of finding

$$
\operatorname{Inf}_{A \in \mathscr{F}_{n}} W_{i}(A) W_{i}\left(A^{*}\right)
$$

for values of $i$ other than $n-1$. Contributions towards solving the problem for $i=0$ have been made by Dvoretzky and Rogers [6], Bambah [2] and recently by Guggenheimer [8]. However, a complete solution for $i=0$ is not yet available. For $0<i<n-1$ the problem is open.

\section{REFERENCES}

1. A. D. Aleksandrov, Neue Ungleichungen zwischen den gemischten Volumina und ihre Andwendungen, Math. Sbornik N. S., 2 (1937), 1205-1238.

2. R. P. Bambah, Polar reciprocal convex bodies, Proc. Cambridge Philos. Soc., 51 (1955), 377-378.

3. L. Bieberbach, Über eine Extremaleigenschaft des Kreises, Jber. Dtsch. Math. Ver., 24 (1915), 247-250.

4. T. Bonnesen and W. Fenchel, Theorie der konvexen Körper, Springer, Berlin. 1934, Reprint: Chelsea. New York, 1948.

5. H. Buseman, Convex Surfaces, Interscience, New York, 1958.

6. A. Dvoretzky and C. A. Rogers, Absolute and unconditional convergence in normed linear spaces, Proc. Nat. Acad. Sci., 36 (1950), 192-197.

7. W. J. Firey, The mixed area of a convex body and its polar reciprocal, Israel J. Math., 1 (1963), 201-202.

8. H. Guggenheimer, Polar reciprocal convex bodies, Israel J. Math., 14 (1973), 309-315.

9. H. Hadwiger, Vorlesungen über Inhalt, Oberfläche und Isoperimetrie, Springer, Berlin, 1957.

10. L. A. Santaló, Un invariante afín para los cuèrpos convexos del espacio de $n$ dimensiones, Portug. Math., 8 (1949), 155-161.

11. F. Steinhardt, On distance functions and on polar series of convex bodies, Ph.D. Thesis, Columbia Univ., 1951.

12. P. Urysohn, Mean width and volume of convex bodies in an $n$ dimensional space, Rec. Math. Soc. Math. Moscow, 31 (1924), 477-486. (Russian).

Received January 4, 1974 and in revised form March 25, 1974. 


\section{PACIFIC JOURNAL OF MATHEMATICS}

\section{EDITORS}

RICHARD ARENS (Managing Editor)

University of California

Los Angeles, California 90024

\section{J. DugundJI}

Department of Mathematics University of Southern California Los Angeles, California 90007

D. Gilbarg and J. Milgram

Stanford University

Stanford, California 94305

\section{ASSOCIATE EDITORS}
E. F. BECKENBACH
B. H. NeumanN
F. WoLF
K. YoshiDA

\section{SUPPORTING INSTITUTIONS}

\author{
UNIVERSITY OF BRITISH COLUMBIA \\ CALIFORNIA INSTITUTE OF TECHNOLOGY \\ UNIVERSITY OF CALIFORNIA \\ MONTANA STATE UNIVERSITY \\ UNIVERSITY OF NEVADA \\ NEW MEXICO STATE UNIVERSITY \\ OREGON STATE UNIVERSITY \\ UNIVERSITY OF OREGON \\ OSAKA UNIVERSITY
}

\author{
UNIVERSITY OF SOUTHERN CALIFORNIA \\ STANFORD UNIVERSITY \\ UNIVERSITY OF TOKYO \\ UNIVERSITY OF UTAH \\ WASHINGTON STATE UNIVERSITY \\ UNIVERSITY OF WASHINGTON \\ AMERICAN MATHEMATICAL SOCIETY
}

The Supporting Institutions listed above contribute to the cost of publication of this Journal, but they are not owners or publishers and have no responsibility for its contents or policies.

Mathematical papers intended for publication in the Pacific Journal of Mathematics should be in typed form or offset-reproduced (not dittoed), double spaced with large margins. Underline Greek letters in red, German in green, and script in blue. The first paragraph or two must be capable of being used separately as a synopsis of the entire paper. Items of the bibliography should not be cited there unless absolutely necessary, in which case they must be identified by author and Journal, rather than by item number. Manuscripts, in duplicate, may be sent to any one of the four editors. Please classify according to the scheme of Math. Reviews, Index to Vol. 39. All other communications should be addressed to the managing editor, or Elaine Barth, University of California, Los Angeles, California, 90024.

100 reprints are provided free for each article, only if page charges have been substantially paid. Additional copies may be obtained at cost in multiples of 50 .

The Pacific Journal of Mathematics is issued monthly as of January 1966. Regular subscription rate: $\$ 72.00$ a year (6 Vols., 12 issues). Special rate: $\$ 36.00$ a year to individual members of supporting institutions.

Subscriptions, orders for back numbers, and changes of address should be sent to Pacific Journal of Mathematics, 103 Highland Boulevard, Berkeley, California, 94708.

PUBLISHED BY PACIFIC JOURNAL OF MATHEMATICS, A NON-PROFIT CORPORATION Printed at Jerusalem Academic Press, POB 2390, Jerusalem, Israel.

$$
\begin{gathered}
\text { Copyright (C) } 1975 \text { Pacific Journal of Mathematics } \\
\text { All Rights Reserved }
\end{gathered}
$$




\section{Pacific Journal of Mathematics}

\section{Vol. 58, No. $2 \quad$ April, 1975}

Zvi Artstein and John Allen Burns, Integration of compact set-valued functions . . . . . . . . . 297

Mark Benard, Characters and Schur indices of the unitary reflection group $[321]^{3} \ldots \ldots \ldots . .309$

Simeon M. Berman, A new characterization of characteristic functions of absolutely continuous

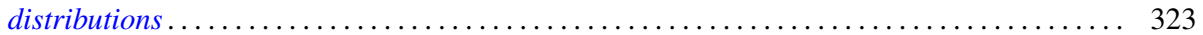

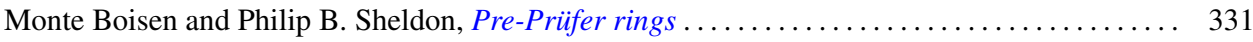

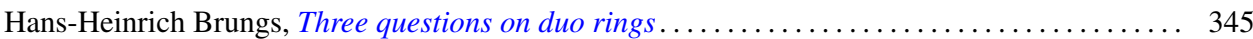

Iracema M. Bund, Birnbaum-Orlicz spaces of functions on groups................. 351

John D. Elwin and Donald R. Short, Branched immersions between 2-manifolds of higher

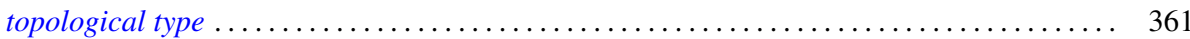

Eric Friedlander, Extension functions for rank 2, torsion free abelian groups . .......... 371

Jon Froemke and Robert Willis Quackenbush, The spectrum of an equational class of

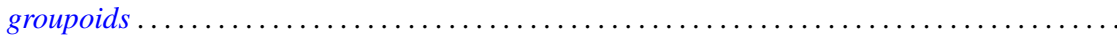

Barry J. Gardner, Radicals of supplementary semilattice sums of associative rings ...........



George Rudolph Gordh, Jr. and Sibe Mardesic, Characterizing local connectedness in inverse

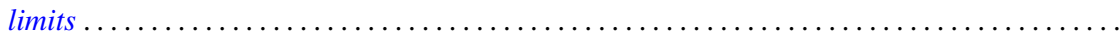

Siegfried Graf, On the existence of strong liftings in second countable topological spaces......

Stanley P. Gudder and D. Strawther, Orthogonally additive and orthogonally increasing

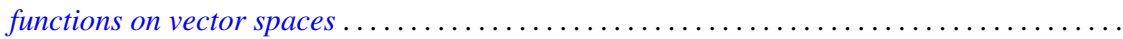

Darald Joe Hartfiel and Carlton James Maxson, A characterization of the maximal monoids and



Robert E. Hartwig and S. Brent Morris, The universal flip matrix and the generalized faro-shuffle. .

William Emery Haver, Mappings between ANRs that are fine homotopy equivalences. .

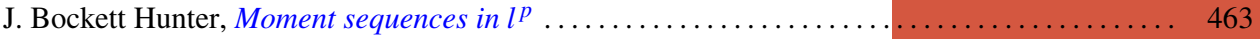

Barbara Jeffcott and William Thomas Spears, Semimodularity in the completion of a poset.... 467

Jerry Alan Johnson, A note on Banach spaces of Lipschitz functions . . . . . . . . . . . . 475

David W. Jonah and Bertram Manuel Schreiber, Transitive affine transformations on

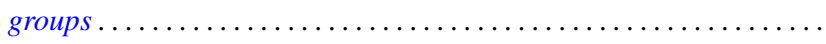

Karsten Juul, Some three-point subset properties connected with Menger's characterization of

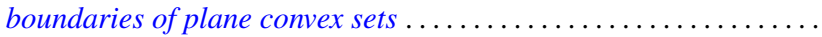

Ronald Brian Kirk, The Haar integral via non-standard analysis . . . . . . . . . . . . . 517

Justin Thomas Lloyd and William Smiley, On the group of permutations with countable

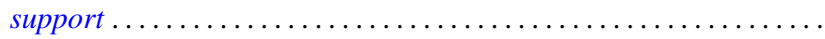

Erwin Lutwak, Dual mixed volumes .................................. 531

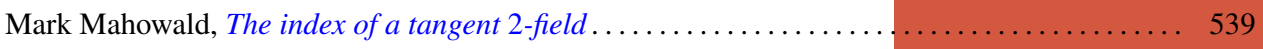

Keith Miller, Logarithmic convexity results for holomorphic semigroups . . . . . . . . . . . . 549

Paul Milnes, Extension of continuous functions on topological semigroups . . . . . . . . . . 553

Kenneth Clayton Pietz, Cauchy transforms and characteristic functions ................ 563

James Ted Rogers Jr., Whitney continua in the hyperspace $C(X) \ldots \ldots \ldots \ldots \ldots \ldots \ldots \ldots .569$

Jean-Marie G. Rolin, The inverse of a continuous additive functional . . . . . . . . . . . . 585

William Henry Ruckle, Absolutely divergent series and isomorphism of subspaces . ........ 605

Rolf Schneider, A measure of convexity for compact sets . ..................... 617

Alan Henry Schoenfeld, Continous measure-preserving maps onto Peano spaces .......... 627

V. Merriline Smith, Strongly superficial elements .......................... 643

Roger P. Ware, A note on quadratic forms over Pythagorean fields . . . . . . . . . . . . . . 651

Roger Allen Wiegand and Sylvia Wiegand, Finitely generated modules over Bezout rings . . . . 655

Martin Ziegler, A counterexample in the theory of definable automorphisms . . . . . . . . . 665 